\title{
Prototipe Monitor dan Kontrol Otomatis Iklim Mikro Greenhouse dengan Platform IoT Blynk
}

\author{
Greenhouse Microclimate Automatic Monitor and Control Protoype with Blynk IoT \\ Platform \\ Dhoni Setyanto ${ }^{1}$, Nur Sultan Salahuddin ${ }^{2}$ \\ ${ }^{1,2}$ Program Studi Teknik Elektro, Universitas Gunadarma \\ E-mail: ${ }^{1}$ dhoni.setyanto@gmail.com, ${ }^{2}$ sultan@staff.gunadarma.ac.id
}

\begin{abstract}
Abstrak
Kenaikan total penduduk setiap waktu berdampak langsung terhadap ketersediaan bahan pangan. Petani seringkali mengalami kerugian akibat dari perubahan iklim yang drastis dan sulitnya memprediksi perubahan iklim tersebut. Penelitian ini bertujuan membuat sistem yang dapat melakukan monitor dan kontrol pada elemen suhu, kelembaban udara, kelembaban tanah serta intensitas cahaya secara otomatis pada greenhouse menggunakan perangkat android lewat platform Internet of Things(IoT) yaitu Blynk. ESP8266 sebagai penghubung jaringan internet antara mikrokontroler dan android sudah tertanam di arduino mega 2560 wifi sehingga tidak membutuhkan komponen modul wifi tambahan. Pada sistem ini dilengkapi dengan kamera ESP32-Cam sehingga sistem juga memantau visual tanaman. Sistem berhasil mendeteksi serta mengukur iklim mikro dalam prototipe greenhouse dengan ukuran panjang $110 \mathrm{~cm}$, tinggi 90 $\mathrm{cm}$, dan lebar $60 \mathrm{~cm}$ menggunakan sensor DHT11 dengan tingkat error sebesar 2,22\% untuk pengukuran suhu, 2,70\% untuk pengukuran kelembaban udara, 3,37\% untuk kelembaban tanah dengan sensor soil moisture, sensor BH1750 tingkat error sebesar 3,49\% untuk intensitas cahaya serta sensor tegangan INA219 dengan nilai error 1,32\%. Hasil dari pembuatan sistem ini adalah sistem beroperasi dengan baik dalam arti keadaan iklim mikro mampu dimonitor dan dikontrol otomatis menggunakan android dengan aplikasi Blynk.
\end{abstract}

Kata kunci: Greenhouse, Iklim Mikro, IoT, Arduino Mega 2560 Wifi, Blynk

\begin{abstract}
The increase of population over time has a direct effect on the availability of food. Farmers often experiencing losses because of significant climate change and difficulty of predicting it. The goal of this research is to create a system that can monitor and control the elements of temperature, air humidity, soil moisture and light intensity automatically in greenhouses using android devices via the Internet of Things (IoT) platform, namely Blynk. ESP8266 as an internet network liaison between the microcontroller and Android is already embedded in the Arduino Mega 2560 wifi so it doesn't need an additional wifi module component. This system is equipped with an ESP32-Cam camera so that the system also monitors plant visuals. The system successfully detects and measures the microclimate in the prototype greenhouse with a length of $110 \mathrm{~cm}$, height $90 \mathrm{~cm}$, and a width of $60 \mathrm{~cm}$ using the DHT11 sensor with an error rate of $2.22 \%$ for measuring temperature, $2.70 \%$ for measuring humidity, 3, 37\% for soil moisture with a soil moisture sensor, BH1750 sensor error rate of 3.49\% for light intensity and INA219 voltage sensor with an error value of $1.32 \%$. The result of making this system is the system operates well in the sense that the microclimate state can be monitored and controlled automatically using Android with the Blynk application.
\end{abstract}

Keywords: Greenhouse, microclimate, IoT, Arduino Mega 2560 wifi, Blynk 


\section{PENDAHULUAN}

Peningkatan jumlah penduduk setiap waktu berdampak langsung terhadap ketersediaan bahan pangan, dikarenakan pangan merupakan salah satu elemen primer untuk kelangsungan hidup manusia. Hortikultura adalah salah satu komoditas bahan pangan yang dibutuhkan penduduk yang menghasilkan protein, serat, vitamin dan lain sebagainya[1]. Tanaman hortikultura memiliki banyak manfaat, diantaranya adalah sumber pemasukan ekonomi, penghasil makanan tambahan, media keindahan dan penghasil tanaman rempah atau obat[2]. Iklim yang mengalami perubahan secara signifikan pada masa sekarang ini bagi petani mengakibatkan bercocok tanam dan musim memanen menjadi tidak menentu dikarenakan cuaca yang tidak pasti[3]. Memprediksi cuaca pada saat musim tanam sulit dilakukan oleh petani sehingga para petani hortikultura maupun tanaman pangan lainnya sering mengalami kerugian. Pada kurun waktu 2015 sampai dengan 2019, terdapat 12 sayuran yang pertumbuhan luas panennya mempunyai nilai negatif dari 22 komoditas, contohnya sawi (-0.29) bawang daun (4.59), dan bayam (-0.81)[4]. Food security index menempatkan Indonesia berada di urutan ke62 yang artinya Indonesia masih berada jauh dibawah negara lain dalam hal ketersediaan, keterjangkauan dan kualitas pangan[5].

Salah satu teknologi alternatif untuk mengendalikan kondisi cuaca atau iklim mikro adalah teknologi greenhouse atau rumah tanaman[6]. Greenhouse adalah bentuk bangunan berstruktur atap dan dinding yang tembus cahaya dan digunakan sebagai salah satu sarana budidaya tanaman [7]. Melalui sarana greenhouse ini maka petani dapat menanam berbagai jenis tanaman holtikultura sepanjang waktu dan tidak tergantung dengan musim [8]. Tanaman hortikultura akan tumbuh dengan maksimal jika beberapa komponen tersedia dalam jumlah yang sesuai seperti suhu, kelembaban udara, ketersediaan $\mathrm{CO}_{2}$ dan cahaya, yang dari semua itu merupakan unsur pokok didalam proses fotosintesis[9]. Salah satu tanaman holtikultura adalah pakcoy / sawi sendok. Pertumbuhan sawi yang baik memerlukan suhu yang relatif rendah hingga sedang $\left(22^{\circ} \mathrm{C}-33^{\circ} \mathrm{C}\right)$, kelembaban lingkungan $\pm 75 \%$. Suhu sebesar $20^{\circ} \mathrm{C}-32^{\circ} \mathrm{C}$ dan kelembaban $60 \%-80 \%[10]$.

Adanya kecanggihan teknologi Internet of Things (IoT) menjadi salah satu pilihan untuk mengontrol dan memonitoring secara otomatis dari jarak jauh yang diterapkan pada pertanian dengan sistem greenhouse[10]. Internet of Things (IoT) adalah suatu konsep yang mana pertukaran informasi dan interaksi dengan benda disekitar lingkungan dengan perantara jaringan internet sehingga mampu memonitor dan mengontrolnya secara jarak jauh tanpa interaksi secara langsung ataupun manual[11],[12]. Didalam greenhouse kondisi iklim mikro akan dimonitoring secara real time antara lain intensitas cahaya, suhu udara, kelembaban udara dan kelembaban tanah. Melalui pengendalian kondisi lingkungan secara otomatis dan monitor secara jarak jauh maka efisiensi penggunaan sumber daya manusia dan produktivitas hasil dapat dioptimalkan.

Beberapa penelitian sebelumnya terkait sistem otomasi greenhouse antara lain: Penelitian oleh [13] menggunakan mikrokontroler Raspberry Pi dan menggunakan sensor suhu DHT11 untuk mengontrol suhu dan kelembaban udara untuk sensor kedua adalah sensor kelembaban tanah atau soil moisture. Pada penelitian ini perangkat berhasil memonitoring secara real time lewat web dengan aplikasi ThingSpeak akan tetapi monitoring untuk pencahayaan belum dilakukan padahal pertumbuhan tanaman juga dipengaruhi oleh sistem pencahayaan. Penelitian yang kedua oleh [14] yang mana pada penelitian ini menggunakan perangkat mikrokontroler Arduino Uno dan NodeMCU sebagai penghubung dengan jaringan internet. Pada penelitian ini alat dapat memonitoring dan melakukan fungsi kontrol secara otomatis dan dapat diakses dari jarak jauh lewat web melalui aplikasi Thinger.Io. akan tetapi pada penelitian ini monitoring dan kontrol terhadap keadaan kelembaban tanah belum dilakukan. Pada penelitian yang ketiga oleh [15] penelitian ini menggunakan Arduino uno dan NodeMCU dan sistem mampu melakukan monitoring dari jarak jauh dengan aplikasi MIT Inventor dan memberikan notifikasi secara otomatis jika di dalam greenhouse kekurangan air ataupun cahaya. Namun didalam sistem ini perangkat wifi masih terpisah dari perangkat utama. Penelitian keempat oleh [16] yang 
menggunakan mikrokontroler NodeMCU. Pada penelitian ini sistem monitoring jarak jauh dapat bekerja dengan baik dengan data monitoring mampu disimpan dengan akurasi 99,76\% namun pada penelitian ini monitoring dilakukan dengan perangkat komputer. Penelitian ke lima oleh [17] menggunakan mikorokontroler Arduino Uno dan modul ESP8266 sebagai penghubung ke jaringan internet, menggunakan sensor kelembaban tanah dan sensor suhu. Sistem berhasil bekerja dengan baik selama pengujian 24 jam yang di monitor lewat aplikasi Blynk dengan android yang menghasilkan kontrol kelembaban tanah antara 30\% - 80\% yang sesuai kebutuhan tanaman tomat pada greenhouse, namun dalam penelitian ini untuk monitor dan kontrol pencahayaan belum dilakukan dan perangkat wifi masih terpisah dengan mikrokontrolernya. Penelitian ke enam oleh [18] dengan mikrokontroler Arduino Nano dan Modul GSM SIM 800 untuk komunikasi ke jaringan internet. Dengan aplikasi IoT MQTT protokol sistem berhasil memonitor suhu dan kelembaban dengan rata-rata error sensor $7.22 \%$ dan selisih suhu 0.9 derajat celcius namun dalam penelitian ini masih menggunakan modul GSM untuk komunikasi dengan jaringan internet yang terpisah dengan mikrokontrolernya.

Melihat dari latar belakang di atas, tujuan utama penulis adalah menyusun suatu alat yang berfungsi untuk monitoring dan mengontrol keadaan iklim mikro didalam greenhouse yaitu suhu, kelembaban udara, kelembaban tanah dan intensitas cahaya sehingga tercapainya kondisi yang optimal yang sesuai dengan kebutuhan tanaman yang bermanfaat bagi pertumbuhan tanaman serta mampu mengirimkan notifikasi jika terjadi perubahan kondisi didalam greenhouse lewat android dengan menggunakan aplikasi Internet of Things (IoT) yaitu Blynk. Dari uraian beberapa penelitian sebelumnya perbedaan yang dilakukan penulis antara lain menggunakan mikrokontroler Arduino Mega 2560 Wifi yang mana sudah tertanam modul wifi, selain itu dalam mengoptimalkan kendali iklim mikro penulis menggunakan sensor suhu dan kelembaban udara(DHT11), sensor kelembaban tanah (soil moisture), sensor intensitas cahaya (BH1750), sensor ultrasonic HC-SR04 untuk memonitor ketersediaan air dalam penampung air serta penulis menambahkan sumber tegangan (daya) dari tenaga surya (PLTS) yang di monitoring dengan sensor tegangan INA219 sehingga sistem dapat diterapkan didaerah yang jauh dari jangkauan listrik. Selain memonitoring data lingkungan didalam greenhouse di tambahkan perangkat camera ESP32-Cam untuk memonitor fisik pertumbuhan tanaman. Semua aktivitas pembacaan sensor dan kendali aktuator serta pengambilan gambar diakses lewat android secara real time melalui aplikasi Blynk.

\section{METODE PENELITIAN}

Pelaksanaan penelitian dimulai dengan konsep studi literatur hingga desain alat, desain perangkat keras, desain perangkat lunak, pembuatan alat, dan pengujian verifikasi. Setelah desain selesai, instrumen yang dibuat dapat dikalibrasi dan diuji kemudian dapat digunakan untuk melakukan pengujian instrumen, pengujian pengiriman data, dan pengujian alat. Gambar 1 adalah diagram alir penelitian dari desain konseptual hingga instrumentasi uji. 


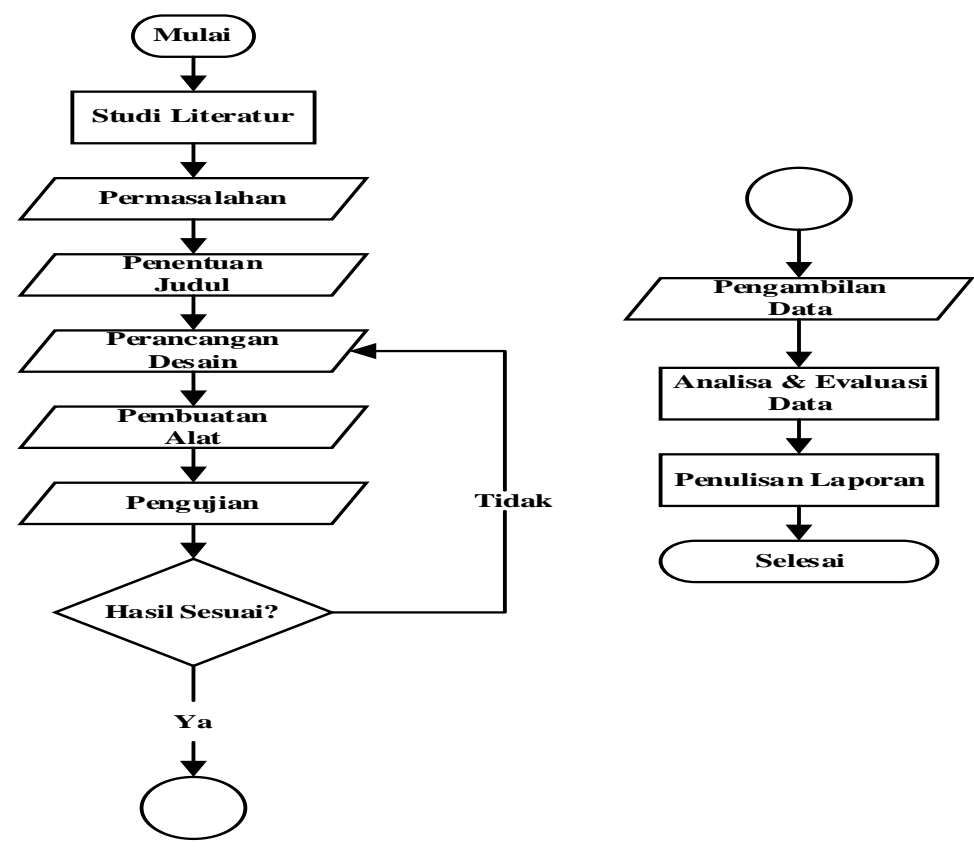

Gambar 1 Diagram Alir Konseptual

Penjelasan gambar 1 di atas adalah sebagai berikut :

a. Study Literature : melakukan study literature melalui jurnal-jurnal yang berhubungan dengan masalah yang diteliti, hasil penelitian orang lain, data sheet, dan buku-buku ilmiah yang sesuai.

b. Permasalahan : melakukan perbandingan data-data tentang kebutuhan penelitian.

c. Penentuan Judul : judul ditentukan untuk memenuhi gap permasalahan dari penelitianpenelitian sebelumnya.

d. Perancangan desain : dimulai dari merancang diagram blok sistem (blok masukan-blok proses-blok keluaran) beserta sumber tegangan; perangkat keras; dan merancang software yang digunakan dalam penelitian. Tahapan ini juga termasuk menggambar skema rangkaian alat, membuat coding/source code pada Arduino IDE, dan pemrograman pada aplikasi Blynk.

e. Pembuatan alat : membuat alat berbentuk prototipe.

f. Pengujian : melakukan pengujian alat dan sensor. Hal ini bertujuan untuk memastikan bahwa alat bekerja sesuai dengan pemrograman, serta memastikan pembacaan sensor sesuai dengan alat ukur (error pembacaan sensor $<5 \%$ ). Jika alat dan sensor telah bekerja sesuai dengan perancangan maka dilanjutkan ke tahap pengambilan data.

g. Pengambilan data.

h. Analisa dan evaluasi : membandingkan data hasil pengujian sebelum dan sesudah dilakukan otomasi serta dianalisa berdasarkan referensi yang sesuai untuk dibuat kesimpulan.

i. Penulisan laporan.

\section{a. Diagram Blok Sistem}

Sistem diagram blok adalah komponen paling esensial dalam penyusunan alat ini, karena diagram blok diketahui cara kerja alat secara keseluruhan. Blok diagram terdiri dari rancangan blok input (masukan), rancangan blok proses, dan rancangan blok output (keluaran) serta untuk memberi tegangan dari solar charger controler. Dimana setiap blok memiliki fungsi yang berbeda-beda. Gambar 2. menunjukkan diagram blok sistem. 


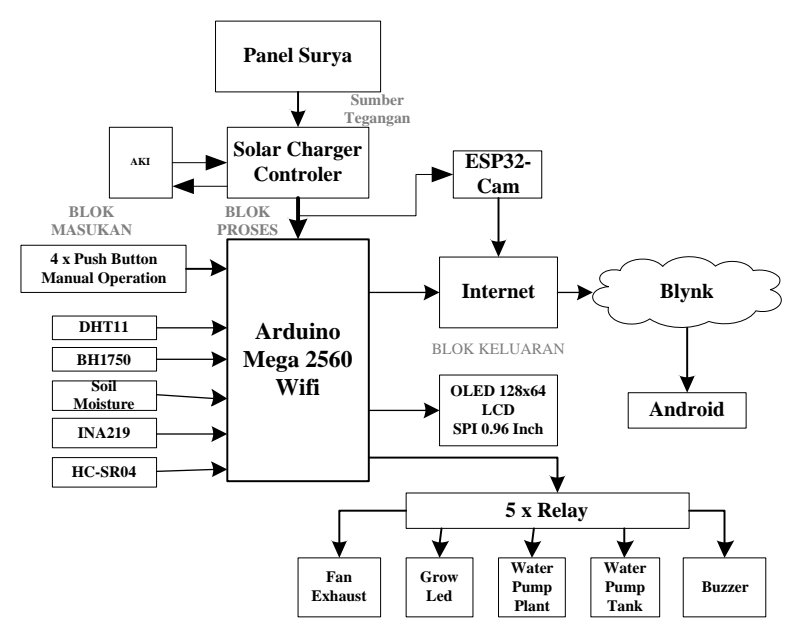

Gambar 2 Blok Diagram Sistem

Berdasarkan gambar di atas menunjukan blok diagram sistem secara keseluruhan yang diterapkan dalam penelitian. Perangkat sistem monitoring dan otomasi kontrol iklim mikro didalam greenhouse terhubung ke mikrokontroler arduino Mega 2560 Wifi sebagai pemroses untuk data input/output atau I/O. Pada perangkat monitoring aplikasi Blynk menampilkan hasil informasi data suhu, kelembaban, $\mathrm{pH}$ tanah, tegangan solar panel dan ketersediaan air serta capture gambar dari kamera ESP32-Cam. Proses monitoring dan kendali menggunakan smartphone.

\section{b. Perancangan Perangkat Keras}

Dalam penelitian ini penulis menggunakan Arduino Mega 2560 wifi sebagai mikrokontroler kemudian terhubung dengan sensor DHT11, sensor BH1750, sensor soil moisture, sensor INA219, sensor HC-SR04, LCD Oled 0.96", modul relay, dan power supply $12 \mathrm{~V}$ serta tombol manual. Sensor DHT11 berfungsi untuk deteksi suhu dan kelembaban udara, sensor BH1750 berfungsi untuk deteksi nilai intensitas cahaya, sensor soil moisture berfungsi untuk deteksi kelembaban tanah, sensor INA219 berfungsi untuk deteksi nilai tegangan searah $(D C)$ yang dipasang dikeluaran solar charger controller sehingga kestabilan tegangan dapat dipantau, sensor HC-SR04 berfungsi untuk deteksi ketersediaan air, modul ESP8266 sudah tertanam didalam mikrokontroler Arduino Mega 2560 Wifi berfungsi menghubungkan jaringan wifi untuk koneksi internet dan aplikasi Blynk, LCD Oled 0.96" berfungsi sebagai penampil data yang terekam oleh sensor, lima buah modul relay digunakan sebagai saklar nyala dan mati fan cooler, pompa irigasi, lampu grow light, pompa pengisi tangki air dan LED buzzer, yang diberi daya sebesar $12 \mathrm{~V}$, dimana power supply $12 \mathrm{~V}$ yang berguna sebagai sumber listrik untuk menyalakan sistem bersumber pada panel surya lewat keluaran solar charger controller. Untuk tombol manual digunakan untuk menyalakan relay secara manual. Serta tak lupa penulis menambahkan perangkat ESP32-Cam untuk mengambil data gambar fisik pertumbuhan tanaman yang terhubung dengan penurun tegangan 5V. Skema rancangan hardware sistem monitor dan pengontrol iklim mikro greenhouse dapat dilihat pada Gambar 3. 


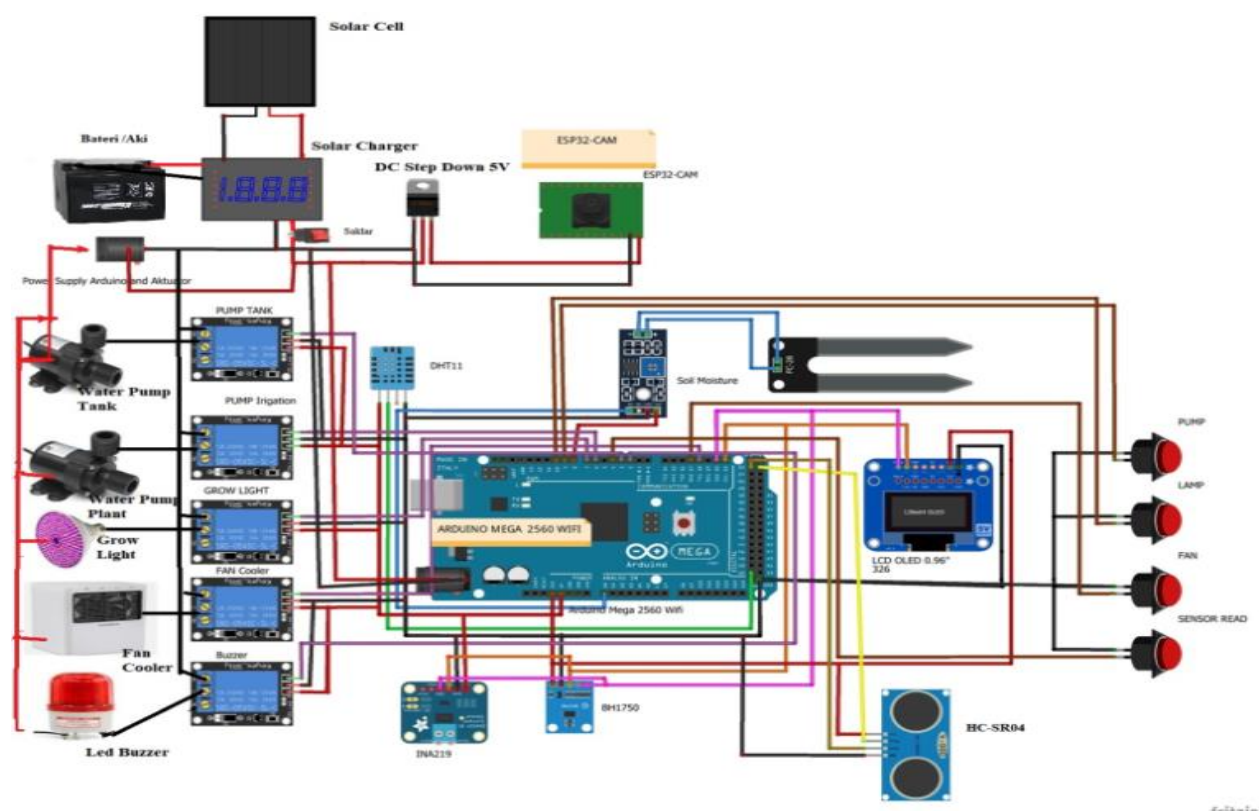

Gambar 3 Skema Rangkaian Alat

\section{c. Perancangan Software Pada Sistem}

Perancangan software yang penulis lakukan dalam penelitian ini menggunakan software Arduino IDE untuk membuat program yang terintegrasi dengan aplikasi Blynk yang akan dipakai dalam memonitoring suhu dan kelembaban udara, kelembaban tanah, intensitas cahaya, tegangan keluaran control charger panel surya, ketersediaan air serta capture gambar tanaman. Perangkat lunak tersebut bisa digunakan untuk berbagai jenis papan Arduino termasuk juga mikrokontroler Arduino Mega 2560 Wifi.

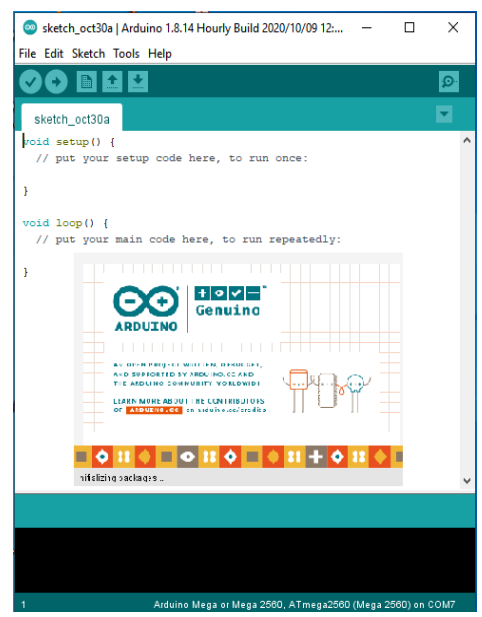

(a)

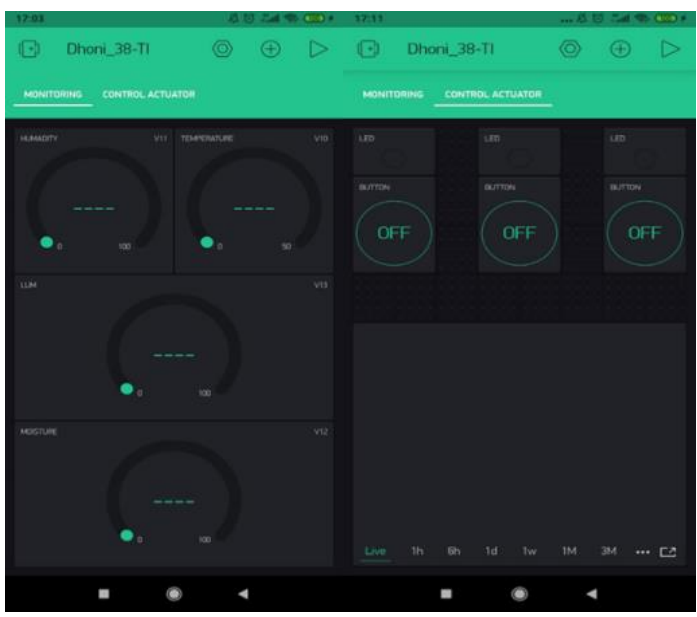

(b)

Gambar 4 Aplikasi Software (a) Arduino IDE dan (b) Blynk

Rancangan diagram software pada bagian pengendali iklim mikro pada greenhouse dapat dilihat pada gambar 5(a) dan (b), dimana modul relay berfungsi sebagai saklar on dan off untuk setiap alat akan bekerja secara otomatis berdasarkan besar nilai yang terekam oleh sensor yang diprogram oleh pengguna. Relay juga bisa dikendalikan secara manual jika sistem otomatis tidak bisa berjalan dengan menekan tombol push button dengan nilai input bernilai Low. Mikrokontroler memberikan perintah untuk nyala dan mati pada relay dengan memberikan 
setting logic low dan on sesuai dengan bahasa pemograman tiap-tiap relay [19]. Pada pembuatan alat ini logic yang dipakai adalah low untuk nyala dan high untuk mati.

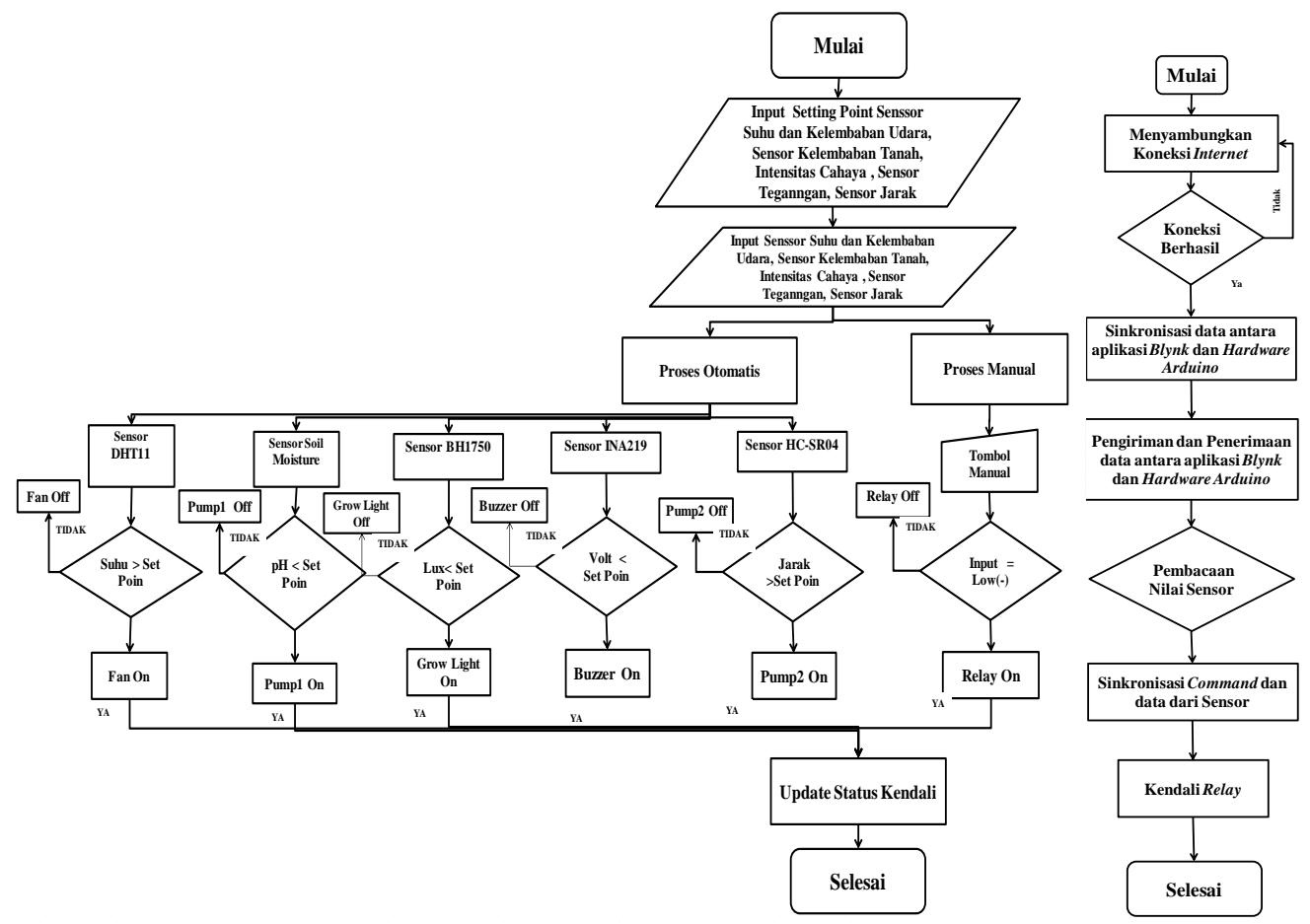

Gambar 5 Flowchart (a) sistem kendali pada Arduino Mega 2560 Wifi dan (b) koneksi ke Blynk

\section{d. Pengujian Alat dan Sistem Pemantau dan Pengendali}

Proses pengujian alat dan sistem bertujuan untuk mengetahui apakah alat dan sistem untuk memantau dan mengendalikan iklim mikro pada greenhouse berbasis aplikasi IoT Blynk dapat berfungsi dan bekerja sesuai dengan rancangan serta menemukan kekurangan (error) terhadap alat dan sistem yang sudah dibuat. Pengujian tersebut meliputi alat dan sistem diantaranya pengujian terhadap sensor, pengujian konektifitas jaringan internet dengan Arduino Mega 2560 Wifi, pengujian sistem secara keseluruhan, serta pengujian tampilan pada perangkat Android. Pengujian sensor dengan cara membandingkan data yang terbaca oleh sensor dengan alat ukur sedangkan pengujian sistem yang sudah dibuat difokuskan pada pengambilan data yang menunjukkan perbandingan iklim mikro pada greenhouse sebelum diterapkan sistem otomasi dan setelah diterapkannya sistem otomasi sehingga akan ditemukan perbedaannya (standar deviasi) berdasarkan setting point terhadap pembacaan sensor yang sudah ditetapkan.

\section{HASIL DAN PEMBAHASAN}

\section{a. Prototipe Greenhouse}

Prototipe greenhouse yang digunakan dalam penelitian ini bertujuan untuk meletakkan panel board, sensor dan alat-alat bagian kendali yaitu fan cooler, LED grow light, pompa irigasi/pengairan, buzzer, ESP32-Cam serta tanaman packcoy dengan media tanam pot serta memberikan batasan ruang kerja untuk sistem yang dijalankan. Prototipe greenhouse dapat dilihat pada gambar 6, dimana prototipe greenhouse yang dibuat adalah greenhouse dengan jenis goble roof even span serta memiliki ukuran panjang $110 \mathrm{~cm}$, lebar $60 \mathrm{~cm}$, dan tinggi 90 $\mathrm{cm}$. Untuk rangka greenhouse dibuat dari balok kayu dan ditutup dengan menggunakan plastik $U V$ yang memiliki ketebalan $0.04 \mathrm{~mm}$ pada semua bagian kecuali bagian bawah. 


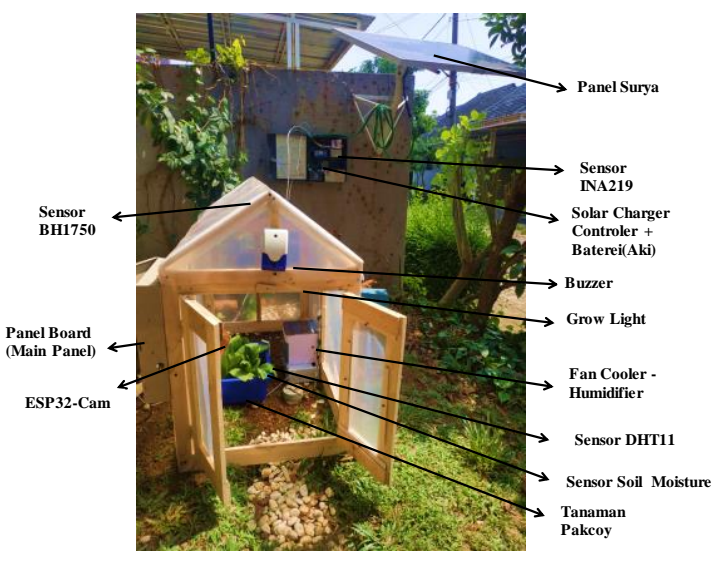

(a)

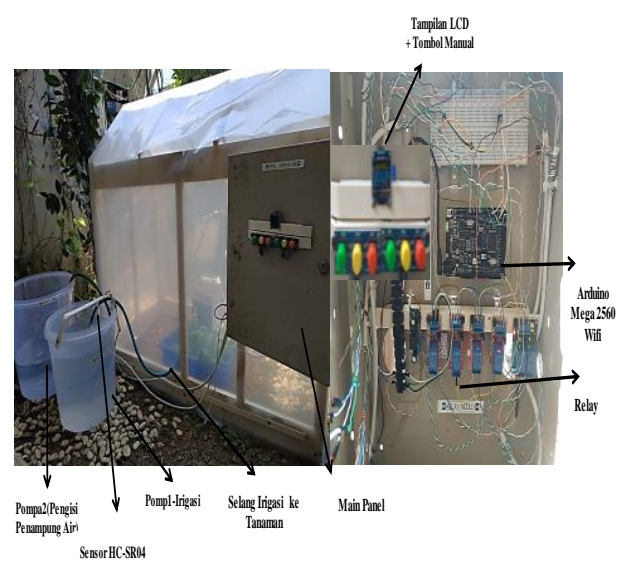

(b)

Gambar 6 Prototipe Greenhouse (a) tampak depan dan (b) tampak samping

\section{b. Pengujian Sensor}

Pengujian sensor yang terhubung dengan mikrokontroler dilakukan agar mengetahui kesalahan sensor yang digunakan jika dibandingkan dengan alat ukur sebenarnya. Pada pengujian sensor DHT11 digunakan alat ukur HTC Digital Air Temperature and Humidity Meter untuk membandingkan hasil pengukuran suhu dan kelembaban udara, alat ukur GM1010 Digital Air Light Meter untuk membandingkan hasil pengukuran sensor BH1750, alat ukur Three Way Meter untuk membandingkan hasil pengukuran sensor soil moisture(YL-69), alat ukur Digital Multitester DT-15 untuk membandingkan hasil pengukuran sensor INA219. Hasil pengukuran akan dihitung menggunakan perhitungan :

Error Sensor $=\left|\frac{\text { Pengukuran Sensor-Pengukuran Alat }}{\text { Pengukuran Alat }}\right| X 100 \%$

Tabel 1 Hasil Kalibrasi Sensor DHT 11

\begin{tabular}{|c|c|c|c|c|c|c|c|c|}
\hline \multicolumn{9}{|c|}{ Hasil Pengukuran } \\
\hline \multirow{2}{*}{ Data Ke- } & \multicolumn{2}{|l|}{ Alat Ukur } & \multicolumn{2}{|c|}{ Pembacaan Sensor } & \multicolumn{2}{|c|}{ Selisih Pengukuran } & \multicolumn{2}{|l|}{ Error (\%) } \\
\hline & Temp $\left({ }^{\circ} \mathrm{C}\right)$ & RH (\%) & Temp $\left({ }^{\circ} \mathrm{C}\right)$ & RH $(\%)$ & Temp $\left({ }^{\circ} \mathrm{C}\right)$ & RH $(\%)$ & Temp (\%) & $\mathrm{RH}(\%)$ \\
\hline 1 & 30,10 & 63 & 29,7 & 65 & 0,40 & 2 & 1,33 & 3,17 \\
\hline 2 & 30,20 & 62 & 29,80 & 64 & 0,40 & 2 & 1,32 & 3,23 \\
\hline 3 & 30,20 & 62 & 29,60 & 65 & 0,60 & 3 & 1,99 & 4,84 \\
\hline 4 & 30,00 & 63 & 29,40 & 66 & 0,60 & 3 & 2,00 & 4,76 \\
\hline 5 & 30,20 & 63 & 31,00 & 64 & 0,80 & 1 & 2,65 & 1,59 \\
\hline 6 & 30,30 & 63 & 30,10 & 65 & 0,20 & 2 & 0,66 & 3,17 \\
\hline 7 & 29,50 & 66 & 28,40 & 67 & 1,10 & 1 & 3,73 & 1,52 \\
\hline 8 & 29,40 & 66 & 28,20 & 67 & 1,20 & 1 & 4,08 & 1,52 \\
\hline 9 & 28,50 & 69 & 27,60 & 70 & 0,90 & 1 & 3,16 & 1,45 \\
\hline 10 & 28,60 & 69 & 27,70 & 70 & 0,90 & 1 & 3,15 & 1,45 \\
\hline 11 & 26,50 & 72 & 26,01 & 73 & 0,49 & 1 & 1,85 & 1,39 \\
\hline 12 & 26,40 & 72 & 25,59 & 74 & 0,81 & 2 & 3,07 & 2,78 \\
\hline 13 & 25,90 & 72 & 25,56 & 75 & 0,34 & 3 & 1,31 & 4,17 \\
\hline 14 & 25,80 & 72 & 25,40 & 74 & 0,40 & 2 & 1,55 & 2,78 \\
\hline 15 & 25,70 & 73 & 25,32 & 75 & 0,38 & 2 & 1,48 & 2,74 \\
\hline \multicolumn{5}{|c|}{ Rata-rata } & 0,63 & 1,8 & 2,22 & 2,70 \\
\hline
\end{tabular}

Tabel 1 merupakan hasil kalibrasi yang bertujuan untuk mengetahui selisih dan persentase error antara pembacaan sensor dengan yang terbaca dengan alat ukur atau tester agar mendekati nilai suhu dan kelembaban udara aslinya. Diketahui suhu dan kelembaban udara yang terbaca 
pada sensor memiliki rata-rata selisih dalam pembacaan suhu udara sebesar $0,53^{\circ} \mathrm{C}$ sedangkan selisih pembacaan kelembaban udara sebesar $1,8 \%$. Untuk rata-rata error mencapai $2,22 \%$ untuk pembacaan suhu udara dan 2,70\% untuk pembacaan kelembaban udara. Dari hasil error kalibrasi yang telah dihasilkan, sensor memiliki kualitas dan bekerja yang baik sesuai dengan datasheet sensor DHT11 yang menyatakan sensor bekerja dengan baik jika memiliki nilai error $<5 \%$ [24].

Tabel 2 Hasil Kalibrasi Sensor Soil Moisture

\begin{tabular}{|l|l|l|l|l|l|}
\hline $\begin{array}{l}\text { Data } \\
\text { Ke- }\end{array}$ & $\begin{array}{l}\text { Alat } \\
\text { Ukur(\%) }\end{array}$ & Sensor (\%) & $\begin{array}{l}\text { Kondisi } \\
\text { Tanah }\end{array}$ & Selisih & Error(\%) \\
\hline 1 & 12 & 12,46 & Dry & 0,46 & 3,83 \\
\hline 2 & 24 & 24,02 & Dry & 0,02 & 0,08 \\
\hline 3 & 30 & 30,76 & Dry & 0,76 & 2,53 \\
\hline 4 & 44 & 46,56 & Moist & 2,56 & 5,82 \\
\hline 5 & 58 & 58,37 & Moist & 0,37 & 0,64 \\
\hline 6 & 64 & 68,66 & Moist & 4,66 & 7,28 \\
\hline 7 & 73 & 74,78 & Moist & 1,78 & 2,44 \\
\hline 8 & 82 & 86,37 & Wet & 4,37 & 5,33 \\
\hline 9 & 90 & 92,17 & Wet & 2,17 & 2,41 \\
\hline Rata-rata & & & 1,91 & 3,37 \\
\hline
\end{tabular}

Dari tabel 2 diketahui hasil kalibrasi sensor kelembaban tanah yang terbaca pada sensor dan soil moisture tester memiliki rata-rata selisih $1,91 \%$ dan rata-rata error mencapai 3,37\%. Nilai rata-rata error kurang dari $5 \%$ hasil tersebut sesuai menyatakan sensor bekerja dengan baik apabila mempunyai nilai error kurang dari 5\%[20].

Tabel 3. Hasil Kalibrasi Sensor BH1750 Dan Sensor INA219

\begin{tabular}{|c|c|c|c|c|c|c|c|c|}
\hline \multicolumn{9}{|c|}{ Hasil Pengukuran } \\
\hline \multirow{2}{*}{$\begin{array}{c}\text { Data } \\
\text { Ke- }\end{array}$} & \multicolumn{2}{|c|}{ Alat Ukur } & \multicolumn{2}{|c|}{ Pembacaan Sensor } & \multicolumn{2}{|c|}{ Selisih Pengukuran } & \multicolumn{2}{|c|}{ Error $(\%)$} \\
\hline & Cahaya(Lux) & $\begin{array}{l}\text { Volt } \\
(\mathrm{V})\end{array}$ & Cahaya(Lux) & Volt(V) & Cahaya(Lux) & $\begin{array}{l}\text { Volt } \\
(\mathrm{V})\end{array}$ & (Lux) & $(\mathrm{V})$ \\
\hline 1 & 24 & 3 & 23,0 & 3,00 & 1,00 & 0 & $4,17 \%$ & $0,00 \%$ \\
\hline 2 & 49 & 3,3 & 48,0 & 3,25 & 1,00 & 0,05 & $2,04 \%$ & $1,52 \%$ \\
\hline 3 & 76 & 3,7 & 75,0 & 3,68 & 1,00 & 0,02 & $1,32 \%$ & $0,54 \%$ \\
\hline 4 & 98 & 4 & 94,0 & 3,95 & 4,00 & 0,05 & $4,08 \%$ & $1,25 \%$ \\
\hline 5 & 110 & 4,5 & 102,0 & 4,42 & 8,00 & 0,08 & $7,27 \%$ & $1,78 \%$ \\
\hline 6 & 225 & 4,8 & 220,0 & 4,75 & 5,00 & 0,05 & $2,22 \%$ & $1,04 \%$ \\
\hline 7 & 660 & 5 & 630,0 & 4,95 & 30,00 & 0,05 & $4,55 \%$ & $1,00 \%$ \\
\hline 8 & 1290 & 5,5 & 1240,0 & 5,44 & 50,00 & 0,06 & $3,88 \%$ & $1,09 \%$ \\
\hline 9 & 1660 & 6 & 1610,0 & 5,89 & 50,00 & 0,11 & $3,01 \%$ & $1,83 \%$ \\
\hline 10 & 1889 & 7,7 & 1830,0 & 7,58 & 59,00 & 0,12 & $3,12 \%$ & $1,56 \%$ \\
\hline 11 & 2100 & 8,6 & 2050,0 & 8,44 & 50,00 & 0,16 & $2,38 \%$ & $1,86 \%$ \\
\hline 12 & 2220 & 9,7 & 2151,0 & 9,51 & 69,00 & 0,19 & $3,11 \%$ & $1,96 \%$ \\
\hline 13 & 2240 & 10,5 & 2153,0 & 10,35 & 87,00 & 0,15 & $3,88 \%$ & $1,43 \%$ \\
\hline 14 & 2280 & 11,5 & 2205,0 & 11,30 & 75,00 & 0,2 & $3,29 \%$ & $1,74 \%$ \\
\hline 15 & 2290 & 11,8 & 2198,0 & 11,65 & 92,00 & 0,15 & $4,02 \%$ & $1,27 \%$ \\
\hline \multicolumn{5}{|c|}{ Rata-rata } & 38,80 & 0,096 & $3,49 \%$ & $1,32 \%$ \\
\hline
\end{tabular}

Dari tabel 3 pengukuran kalibrasi nilai intensitas cahaya yang terbaca pada sensor dan digital light meter memiliki rata-rata selisih 38,80 Lux dan rata-rata error mencapai 3,49\%. Hasil dari pengukuran intensitas cahaya tersebut dikatakan bekerja dengan baik sesuai dengan akurasi minimal sensor BH150 yaitu 92\%[21].

Dari data tabel 3 hasil kalibrasi didapat nilai tegangan yang terbaca pada sensor dan digital multimeter memiliki rata-rata selisih 0,10 volt dan rata-rata error mencapai $1,32 \%$. Hasil tersebut manyatakan bahwa jika sensor bekerja dengan baik yang mana memiliki akurasi lebih dari $95 \%$. 


\section{c. Pengujian Konektifitas ke Server Blynk}

Pengujian dilakukan dengan tujuan untuk mengetahui apakah platform IoT Blynk yang digunakan untuk penelitian efektif dalam sistem monitoring dan kendali jarak jauh. Gambar 7 adalah hasil dari pengujian konektifitas ke server Blynk

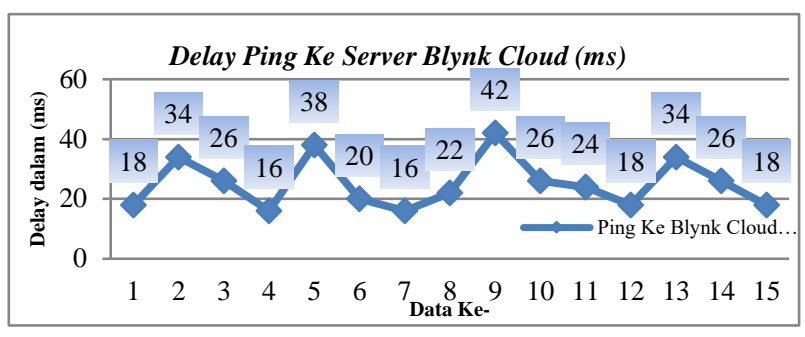

Gambar 7 Grafik Hasil Pengujian Konektifitas ke Server Blynk

Dari hasil pembacaan grafik gambar 7 hasil nilai rata-rata delay yang didapat sebesar 25,2 ms, menurut standarisasi delay dari TIPHON nilai rata-rata delay pada pengujian ini masih dalam kategori sangat bagus[22]. Hal ini memberikan indikasi jika aplikasi Blynk masih terbilang efektif untuk digunakan dalam sistem monitoring secara jarak jauh.

\section{d. Pengujian Sistem Secara Keseluruhan}

Pengujian sistem secara keseluruhan dilakukan dilakukan selama dua hari yaitu pada tanggal 7/10/2021 dan Tanggal 9/10/2021. Pengambilan data dilakukan pada kondisi cuaca yang sama yaitu kondisi cerah dan dilakukan dari jam 8.15 WIB sampai dengan jam 16.00 WIB. Sesuai dengan tujuan penulis dalam pembuatan alat ini, pengujian sistem secara keseluruhan dilakukan dengan cara membandingkan kondisi iklim mikro antara lain suhu dan kelembaban udara, kelembaban tanah dan intensitas cahaya sebelum menggunakan sistem otomasi dengan setelah menerapkan sistem otomasi pada greenhouse yang dapat dimonitor dan dikendalikan dari jarak jauh menggunakan aplikasi Blynk. Data pembacaan sensor dan pembacaan input/output direkam oleh aplikasi Blynk dan dikirim ke email dalam format CSV sesuai settingan di aplikasi Blynk. Serta dengan menggunakan rumus standar deviasi data hasil monitoring akan dianalisa untuk suhu udara, kelembaban udara dan kelembaban tanah dari sebelum dan sesudah menerapkan sistem otomasi. Berikut rumus standar deviasi:

$$
S=\sqrt{\frac{\sum_{i=i}^{n}(x i-x)^{2}}{n-1}}
$$

Keterangan:

$\mathrm{S}=$ Standar Deviasi, $\mathrm{xi}=$ Nilai sampel, $\mathrm{x}=$ Nilai rata-rata sampel, $\mathrm{n}=$ Jumlah sampel

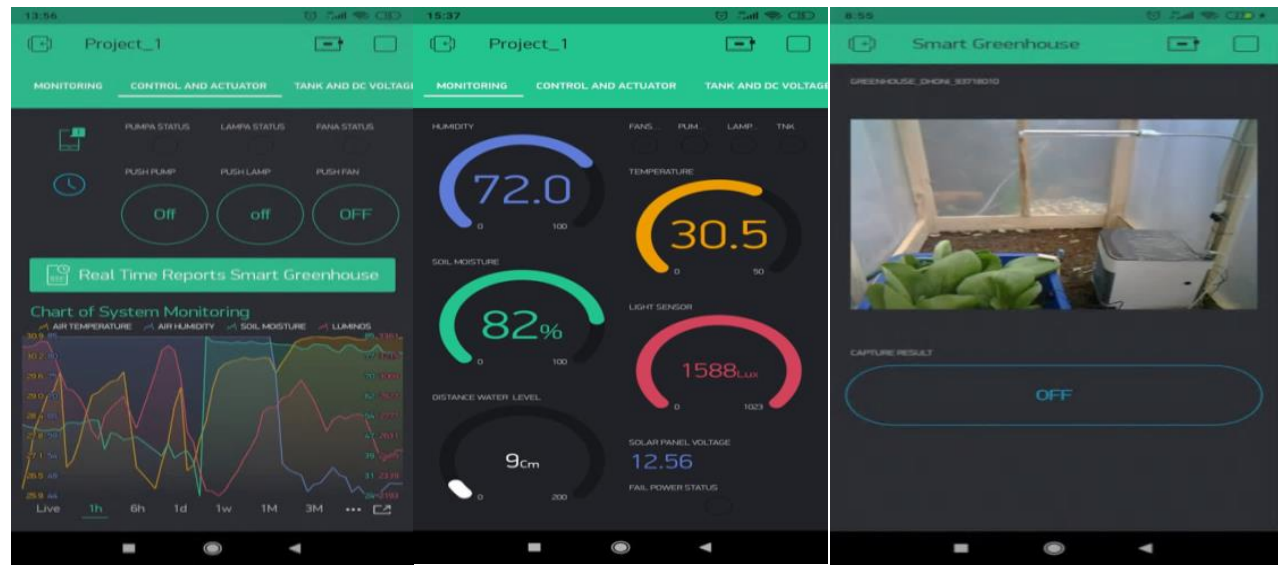

Gambar 8 Hasil Monitoring dengan Aplikasi Blynk 
Hasil Pengujian sebelum dan sesudah menerapkan sistem otomasi adalah sebagai berikut, data ditampilkan dalam bentuk grafik agar memudahkan dalam penganalisaan.

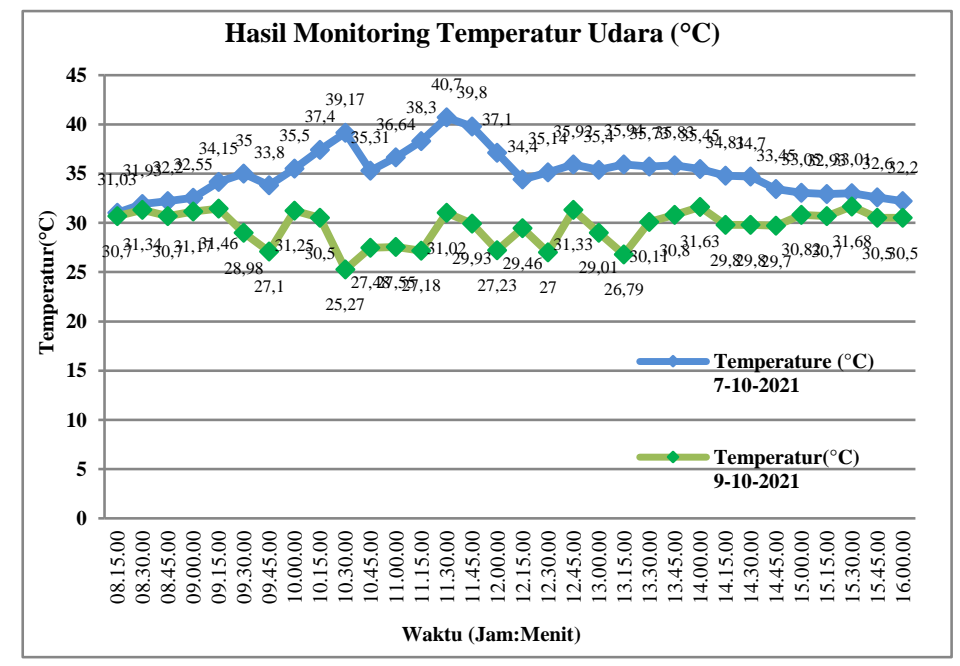

Gambar 9 Hasil Grafik Hubungan Suhu Udara Dengan Waktu

Dari hasil data pengujian sebelum dan sesudah menerapkan sistem otomasi didapatkan suhu udara didalam greenhouse sebelum menerapkan sistem otomasi mengalami fluktuasi suhu yaitu perubahan atau kenaikan suhu secara signifikan pada jam 10.00 sampai 12.00 dikarenakan pada waktu tersebut terjadi perpindahan panas yang seperti diketahui bahwa perpindahan panas pada greenhouse terjadi pada atap, material yang ada pada greenhouse, dan perpindahan panas yang terjadi dengan tanah[23]. Kemudian terjadi penurunan suhu pada jam 12.15 dan sampai jam 16.00. Pada waktu tersebut suhu relatif stabil antara $32^{\circ} \mathrm{C}$ sampai dengan $34^{\circ} \mathrm{C}$. Dari data tabel dan grafik diatas juga didapatkan suhu rata-rata mencapai $35,03^{\circ} \mathrm{C}$. Setelah menerapkan sistem otomasi jika melihat grafik suhu relatif stabil dimana sistem otomasi bekerja dengan maksimal dimana fan coller akan menyala jika suhu mencapai diatas $31^{\circ} \mathrm{C}$. Sistem otomasi berhasil mengoptimalkan persebaran suhu pada rentang $25-31^{\circ} \mathrm{C}$ dengan rata-rata suhu sebesar $29,64^{\circ} \mathrm{C}$. Pada suhu rata-rata tersebut ideal untuk pertumbuhan tanaman holtikultura seperti sawi. Dengan menggunakan persamaan rumus(2) didapatkan nilai standar deviasi sebelum dan setelah menerapkan sistem otomasi adalah $2,36^{\circ} \mathrm{C}$ dan $1,65^{\circ} \mathrm{C}$.

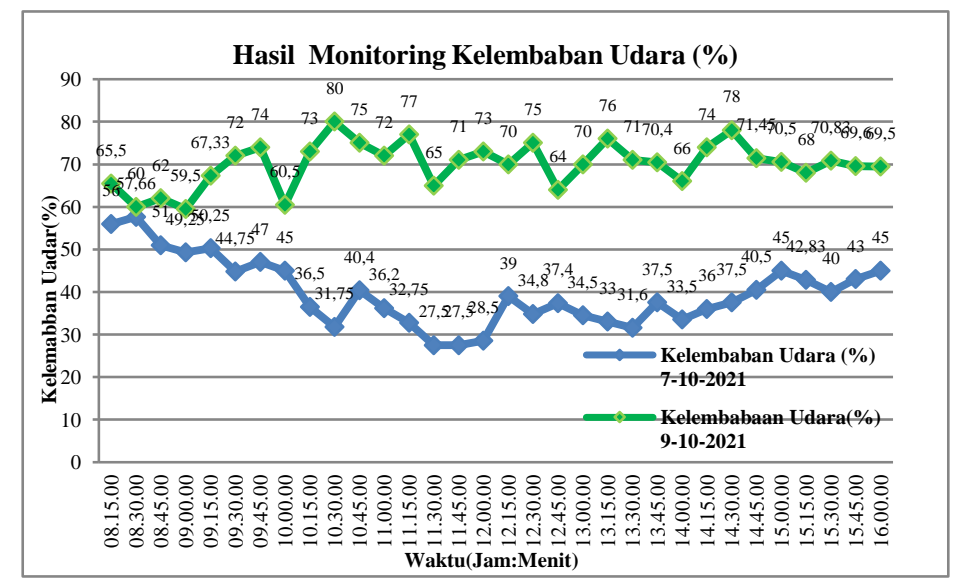

Gambar 10 Hasil Grafik Hubungan Kelembaban Udara Dengan Waktu

Pada data grafik gambar 10 yang telah diperoleh, sebelum menerapkan sistem otomasi terjadi fluktuasi pada jam 10.00 sampai dengan jam 12.00 karena pada waktu tersebut terjadi perpindahan panas didalam greenhouse yang meningkat. kelembaban stabil pada jam 12.15 sampai jam 16.00 dikarenakan penurunan perpindahan panas, dan suhu udara yang mengalami penurunan dimana 
kelembaban dikisaran $31 \%$ sampai dengan $45 \%$. Data setelah otomasi berhasil membuat kelembaban udara merata dan stabil dari pada sebelumnya. Nilai kelembaban antara 60,5\% - 80 $\%$ dengan rata-rata kelembaban udara sebesar 70,03\%, fan cooler bekerja dengan optimal sehingga mampu menjaga kestabilan suhu sehingga berpengaruh juga terhadap kestabilan kelembaban udara. Dari data grafik didapatkan nilai standar deviasi antara sebelum dan sesudah otomasi sebesar $8,22 \%$ dan $4,63 \%$.

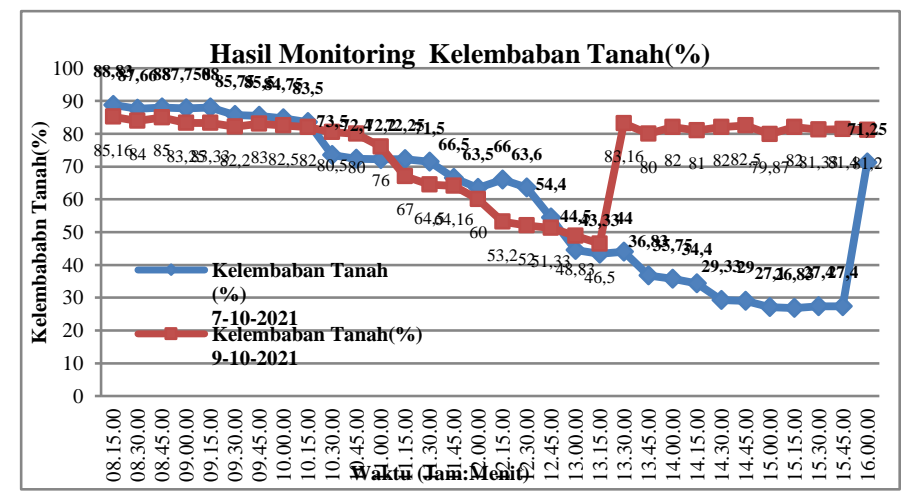

Gambar 11 Hasil Grafik Hubungan Kelembaban Tanah Dengan Waktu

Berdasarkan gambar 11 diatas, sebelum menerapkan sistem otomasi nilai kelembaban tanah stabil pada jam 8.00 WIB sampai dengan jam 10.15 WIB dimana penyiraman manual terjadi pada pukul 8.00 WIB kemudian mengalami penurunan setelahnya. Ini dikarenakan terjadi penyerapan air oleh tanaman dan tanah. Penurunan kelembaban tinggi terjadi setelah jam 13.00 sehingga setelah waktu tersebut kelembaban tanah kurang dari $40 \%$. terjadi kelembaban yang kurang dari $40 \%$ yang terjadi selama sekitar 2,5 jam. Setelah jam 16.00 WIB baru dilakukan penyiraman secara manual dan terjadi kenaikan kelambaban sebesar $71 \%$ dan rata-rata kelembaban sebesar 58,8\%. Setelah menerapkan sistem otomasi didapatkan bahwa kelembaban tanah stabil setelah mengalami penyiraman secara otomatis dimana pompa akan menyala jika kelembaban kurang dari $40 \%$. Hal ini berbeda dengan data yang diperoleh sebelum otomasi yang mengalami penurunan terus menerus sampai proses manual penyiraman dilakukan sehingga kelembaban naik kembali. Dari data grafik dapat dihasilkan rata-rata kelembaban setelah otomasi sebesar $74,71 \%$ sedangkan perbandingann standar deviasinya sebelum dan sesudah menerapkan sistem otomasi sebesar $23,23 \%$ berbanding $12,37 \%$.

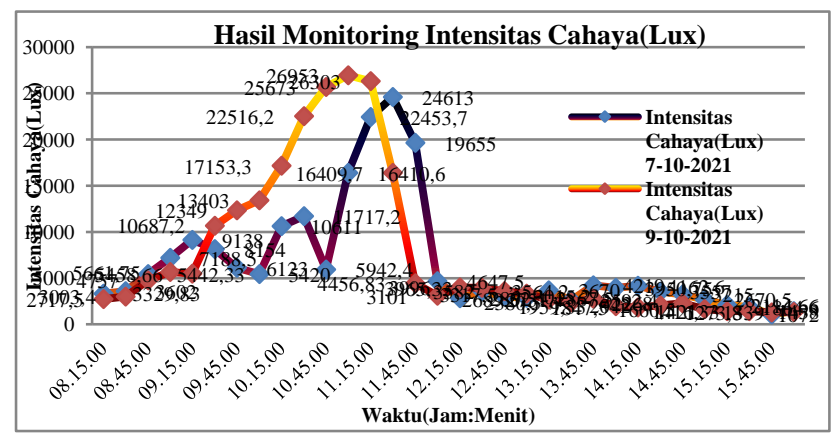

Gambar 12 Hasil Grafik Hubungan Intensitas Cahaya Dengan Waktu

Pada saat pengujian cuaca dalam keadaan cerah sebelum dan sesudah menerapkan sistem otomasi ini bisa dilihat dari hasil data gambar 12 yang diperoleh. Nilai intensitas cahaya pada pagi hari sebesar 3329 lux dan pada sore hari sebesar 1438 Lux. terjadi peningkatkan intensitas cahaya yaitu pada pukul 11.30 yaitu sebesar 24.613 Lux ini disebabkan pada waktu tersebut matahari berada dipuncak penyinaran. Dari data diatas rata-rata intensitas cahaya sebesar 6600 Lux sedangkan untuk nilai setelah otomasi tidak berbeda jauh sehingga pencahayaan untuk tanaman di dalam greenhouse telah tercukupi. 


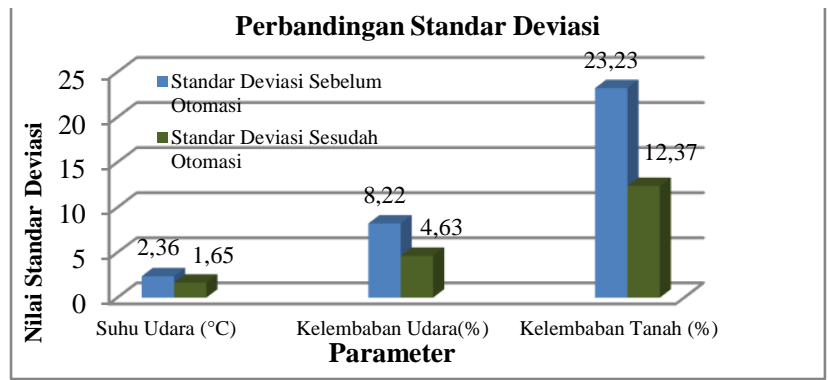

Gambar 13 Hasil Grafik Perbandingan Standar Deviasi Sebelum dan sesudah Otomasi

Berdasarkan data gambar 13 di atas dapat diketahui bahwa nilai standar deviasi suhu udara turun setelah dilakukan otomasi. Nilai standar deviasi merupakan nilai keseragaman data yang diperoleh. Semakin kecil nilai deviasi yang didapat, maka keseragaman data besar. Nilai persebaran data setelah menerapkan sistem otomasi menjadi lebih baik jika dibandingkan dengan nilai persebaran data sebelum otomasi. Nilai persebaran data juga lebih baik pada tiap jam. Sehingga dapat disimpulkan bahwa nilai suhu udara dalam greenhouse relatif stabil disetiap waktu. Untuk kelembaban udara sebelum dan sesudah otomasi juga mengalami perubahan nilai standar deviasi yang besar. Nilai standar deviasi kelembaban udara sebelum otomasi sangat besar sehingga persebaran kelembaban udaranya tidak stabil tiap waktu. Sedangkan nilai standar deviasi setelah dilakukan otomasi menjadi kecil sehingga persebarannya merata dan lebih stabil. Untuk kelembaban tanah juga mengalami penurunan standar deviasi setelah menerapkan sistem otomasi sehingga terjadi kestabilan kondisi kelembaban tanah lebih bisa dipertahankan

\section{KESIMPULAN DAN SARAN}

Dari hasil penelitian yang sudah dilakukan berhasil membangun dan merancang sistem dan prototipe alat yang dapat memantau dan mengendalikan iklim mikro pada greenhouse. Sistem dalam bentuk prototipe greenhouse dengan jenis goble even roof dengan ukuran panjang 110 $\mathrm{cm}$, tinggi $90 \mathrm{~cm}$, dan lebar $60 \mathrm{~cm}$. Pengujian sensor DHT11 memiliki tingkat kesalahan atau error sebesar 2,22\% untuk pengukuran suhu serta 2,70\% untuk nilai error kelembaban udara sedangkan nilai error sensor BH1750 untuk intensitas cahaya sebesar 3,49\%, untuk sensor tegangan INA219 sebesar 1,32\%. Untuk waktu delay saat start up koneksi mikrokontroler ke server Blynk rata-rata $25,2 \mathrm{~ms}$ (milliseconds). Pengujian monitoring dan sistem otomatis kendali dapat bekerja dengan baik sesuai dengan setting point sehingga sistem mampu menurunkan standar deviasi, serta data sensor dan sistem kendali maupun tampilan gambar kondisi fisik tanaman dapat ditampilkan pada aplikasi Blynk.

Dari penelitian ini diharapkan dapat dilanjutkan menambahkan sistem yang mampu mendeteksi binatang pengganggu atau hama tanaman serta dapat melakukan pengambilan keputusan terhadap pencegahannya sehingga tanaman didalam greenhouse terbebas dari binatang pengganggu atau hama tumbuhan.

\section{DAFTAR PUSTAKA}

[1] Aswatini, M. Noveria, and Fitranita, "Konsummsi Sayur Dan Buah Di Masyarakat Dalam Konteks Pemenuhan Gizi Seimbang,” J. Kependud. Indones., vol. III, no. 2, pp. 97-119, 2008, [Online].

[Online]. Available https://ejurnal.kependudukan.lipi.go.id/index.php/jki/article/download/171/203.

[2] E. Tando, "Review: Pemanfaatan Teknologi Greenhouse Dan Hidroponik Sebagai Solusi Menghadapi Perubahan Iklim Dalam Budidaya Tanaman Hortikultura," Buana Sains, vol. 19, no. 1, p. 91, 2019, doi: 10.33366/bs.v19i1.1530. 
[3] E. Aldrian, M. Karmini, and Budiman, "Adaptation and Mitigation of Climate Change in Indonesia (Adaptasi dan Mitigasi Perubahan Iklim di Indonesia)," Pus. Perubahan Iklim dan Kualitas Udar. BMKG, no. 2, p. 174, 2011, [Online]. Available: www.bmkg.go.id.

[4] Kementerian Pertanian, "Sub-sektor Hortikultura (Horticulture Sub-sector)," 2020. https://www.pertanian.go.id/home/?show=page\&act=view\&id=61 (accessed Aug. 10, 2021).

[5] BPS et al., "Buletin Pemantauan Ketahanan Pangan indonesia Fokus Khusus: Tren konsumsi dan produksi buah dan sayur," Ger. Humanit. Assist., vol. 8, no. November, pp. 1-24, 2019, [Online]. Available: https://docs.wfp.org/api/documents/WFP0000024091/download/.

[6] G. R. North, "Greenhouse Effect and Climate Feedbacks 4 . 1 Greenhouse Effect without Feedbacks 4 . 2 Infrared Spectra of Outgoing Radiation," pp. 85-117, 2017.

[7] O. Körner, J. M. Aaslyng, A. U. Andreassen, and N. Holst, "Modelling microclimate for dynamic greenhouse climate control," HortScience, vol. 42, no. 2, pp. 272-279, 2007.

[8] M. A. A. Abdrabbo, A. Negm, H. E. Fath, and A. Javadi, "Greenhouse Management and Best Practice in Egypt," Int. Water Technol. Journal, IWTJ, vol. 9, no. 4, pp. 12-13, 2019.

[9] M. N. Fahmi, E. Yohana, and Sugiyanto, "Simulasi Distribusi Suhu Dan Kelembapan Relatif," J. Tek. Mesin, vol. 2, no. 1, pp. 41-48, 2014.

[10] A. Rifqi Fauzi, Casdi, and Warid, "Respon Tanaman Pakcoy (Brassica rapa L.) terhadap Pemberian Pupuk Organik Cair Limbah Perikanan," J. Hortik. Indones., vol. 10, no. 2, pp. 94-101, 2019, doi: 10.29244/jhi.10.2.94-101.

[11] S. Verma, R. Gala, S. Madhavan, S. Burkule, S. Chauhan, and C. Prakash, "An Internet of Things (IoT) Architecture for Smart Agriculture," Proc. - 2018 4th Int. Conf. Comput. Commun. Control Autom. ICCUBEA 2018, pp. 1-4, 2018, doi: 10.1109/ICCUBEA.2018.8697707.

[12] P. Serikul, N. Nakpong, and N. Nakjuatong, "Smart Farm Monitoring via the Blynk IoT Platform," 2018 16th Int. Conf. ICT Knowl. Eng., pp. 1-6, 2018.

[13] I.Lakshmi, "Design And Implementation Of Greenhouse Automation And Monitoring System Using Iot," Ijarcce, vol. 8, no. 5, pp. 136-140, 2019, doi: 10.17148/ijarcce.2019.8527.

[14] Win Sandar Aung | Saw Aung Nyein Oo, "Monitoring and Controlling Device for Smart Greenhouse by using Thinger.io IoT Server," Int. J. Trend Sci. Res. Dev., vol. 3, no. 4, pp. 1651-1656, 2019, doi: https://doi.org/10.31142/ijtsrd25212.

[15] F. Malinda, N. Sultan, and E. Hasibuan, "Perancangan Sistem Mitigasi Smart Greenhouse Untuk Hidroponik," J. Ilm. Komputasi, vol. 20, no. 2, pp. 247-258, 2021, doi: 10.32409/jikstik.20.2.2711.

[16] D. K. Widyawati, A. Ambarwari, and A. Wahyudi, "Design and Prototype Development of Internet of Things for Greenhouse Monitoring System," 2020 3rd Int. Semin. Res. Inf. Technol. Intell. Syst. ISRITI 2020, pp. 389-393, 2020, doi: 10.1109/ISRITI51436.2020.9315487.

[17] R. Gunawan, T. Andhika, . S., and F. Hibatulloh, "Monitoring System for Soil Moisture, Temperature, $\mathrm{pH}$ and Automatic Watering of Tomato Plants Based on Internet of Things," Telekontran J. Ilm. Telekomun. Kendali dan Elektron. Terap., vol. 7, no. 1, pp. 66-78, 2019, doi: 10.34010/telekontran.v7i1.1640.

[18] A. Sofwan, S. Sumardi, A. I. Ahmada, I. Ibrahim, K. Budiraharjo, and K. Karno, "Smart Greetthings: Smart Greenhouse Based on Internet of Things for Environmental Engineering," Proceeding - ICoSTA 20202020 Int. Conf. Smart Technol. Appl. Empower. Ind. IoT by Implement. Green Technol. Sustain. Dev., pp. 5-9, 2020, doi: 10.1109/ICoSTA48221.2020.1570614124.

[19] W. Vernandhes, N. S. Salahuddin, A. Kowanda, and S. P. Sari, "Smart aquaponic with monitoring and control system based on IoT," Proc. 2nd Int. Conf. Informatics Comput. ICIC 2017, vol. 2018-Janua, pp. 1-6, 2018, doi: 10.1109/IAC.2017.8280590. 
[20] U. Syafiqoh, S. Sunardi, and A. Yudhana, "Pengembangan Wireless Sensor Network Berbasis Internet of Things untuk Sistem Pemantauan Kualitas Air dan Tanah Pertanian," J. Inform. J. Pengemb. IT, vol. 3, no. 2, pp. 285-289, 2018, doi: 10.30591/jpit.v3i2.878.

[21] M. PAMUNGKAS, H. HAFIDDUDIN, and Y. S. ROHMAH, "Perancangan dan Realisasi Alat Pengukur Intensitas Cahaya," ELKOMIKA J. Tek. Energi Elektr. Tek. Telekomun. Tek. Elektron., vol. 3, no. 2, p. 120, 2015, doi: 10.26760/elkomika.v3i2.120.

[22] N. Indah, Y. Salim, and R. Satra, "Analisis Perbandingan Routing Protokol Open Shortes Path First (Ospf) Dengan Enhanced Interior Gateway Routing Protocol (Eigrp)," Ilk. J. Ilm., vol. 10, no. 1, pp. 92-99, 2018, doi: 10.33096/ilkom.v10i1.205.92-99.

[23] M. K. Ghosal, G. N. Tiwari, N. S. L. Srivastava, and M. S. Sodha, "Thermal modelling and experimental validation of ground temperature distribution in greenhouse," Int. J. Energy Res., vol. 28, no. 1, pp. 45-63, 2004, doi: 10.1002/er.950. 